\title{
低炭素鋼の高温延性および溶接割れにおよぼす 窒化アルミの影響*
}

（鋼中の窒化アルミの研究-III）

\author{
長谷部 茂 雄** \\ Effects of Aluminum Nitride on the High-Temperature Ductility \\ and on the Welding Crack of Low-Carbon Steel.
}

(Study on aluminum nitride in steel-III)

Shigeo HASEBE

Synopsis:

Effects of aluminum nitride (AlN) precipitates on the high-temperature ductility and on the welding crack at heat-affected zone were investigated. Small tensile test pieces were made of the steels containing different amounts of aluminum and nitrogen (Table 1 and 2), and were drawn at $500 \sim 1000^{\circ} \mathrm{C}$. The specimens of C.T.S. (controlled thermal severity) test (Fig. 1) were used for the investigation of the welding crack at the heat-affected zone.

1) The high-temperature ductility of low-carbon steel as cast is decreased extremely by the addition of aluminum (Fig. 2 and 3 ). The ductility of low-carbon steel at a temperature lower than $800^{\circ} \mathrm{C}$ is higher than the one of medium-carbon steel.

2) The ductility during rapid-cooled from $1350^{\circ} \mathrm{C}$ of low-carbon steel as cast or as forged is decreased at a temperature higher than $850^{\circ} \mathrm{C}$ by the addition of aluminum (Fig. 5). The ductility of it during slow-cooling from $1350^{\circ} \mathrm{C}$ is not decreased by the addition of aluminum unlike the ductility of medium-carbon steel (Fig. 4). The ductility without preheat-treat ment of low-carbon steel as forged is decreased at a temperature higher than $850=\mathrm{C}$ by the addition of aluminum.

3) Presumably there is a relation between the decrement of the high-temperature ductility of low-carbon steel by the addition of aluminum and the morphology of aluminum nitride in the steel (Photo. 1 and 2).

4) In the heat-affected zone directly under weld-deposit of the steel containing more aluminum and nitrogen, the precipitates of aluminum nitride scatter undissolved by welding heat. The precipitates in the steel containing less aluminum and nitrogen are dissolved in the heat-affected zone by welding heat. The aluminum nitride precipitates which exist dispersedly undissolved by welding heat in the heat-affected zone seem to promote the transformation during cooling after heated by welding heat, and consequently the welding crack in the heat-affected zone (Photo. 3) is decreased by the addition of large quantities of aluminum and nitrogen.

5) Presumably there is a relation between the increment of the welding crack in the heataffected zone by the addition of aluminum up to $0.01 \sim 0.02 \%$ and the decrement of the hightemperature ductility by the addition of aluminum. It is considered that the hot crack in the heat-affected zone initiates on account of the decrement of the high-temperature ductility by the precipitation of aluminum nitride, and that consequently the cold crack in the heataffected zone is increased with the hot crack as its starting point.

6) The welding cracks in the heat-affected zone observed in the steel as cast are much more than those in the steel as forged, and are not decreased by the addition of great quantities of aluminum unlike with the steel as forged. This phenomenon seems to be based on the fact that the ductility at high temperature is decreased by formation of the line of aluminum nitride precipitates and the network of sulphide inclusions.

* 昭和 35 年 10 月本会講演大会にて発表 ** 住友金属工業, 中央技術研究所 


\section{I. 緒言}

本報では，低炭素鋼の高温延性におよばす窒化アルる (AIN) の析出形態の影響を調査して, 前報1)の中炭素 鋼の場合との比較を行なうと同時に, 溶接構造用鋼で問 題となる溶接熱影響部割れにおよぼす A1N の影響につ いて考察した.

$\mathrm{Al}$ の添加によつて鋼中に析出する $\mathrm{AlN}$ が, 鋼の組 織を微細にし，また遊離のNの量が減少する勃果も加わ つて，鋼の䩓性を向上させる勃果のあることなど，低炭 素鋼の性質におよぼす A1N の影響については, かなり よく知られている。

とくに溶接構造用の低炭素鋼においては, 結晶粒の微 細化および昰時効脆化の防止による靶性の向上, さらに 多量の AlN によるフェライト結晶粒の一層の微細化 ${ }^{2)}$, 降伏強度の増加 ${ }^{3)}$ ，ならびに溶接熱影響部の硬化あるい

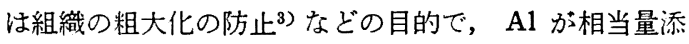
加されるのが普通である. H. WIESTER ら33は, 低炭素 のトーマス鋼の諸性質におよぼす A1N の影響を調査し ているが，平炉鋼においても故意にNを添加して，A1N の析出効果を利用することも考えている.

しふし，低炭素鋼の高温延性ならびに溶接構造用鋼の 溶接熱影響部割れにおよぼす A1N の影響については明 瞭でない. 熱影響部割れは溶接ビード下割れともいわれ るが，これにおよぼす鋼材の含有成分の影響あるいは割 れの発生機構について注く, 多く研究があるが, A1 の 量の影響注とくに複雑であり, 従来の報告にみられる結 果はまちまちである。

\section{II. 実 験 方 法}

\section{1) 供試材}

Table 1 および 2 に供試材の化学成分を示す. C $0 \cdot 20 \%$, Si 0.30\% および Mn 1.3\% 前後の低炭素低 マンガン鋼である. いずれも高周波炉で溶製した $50 \mathrm{~kg}$ 鋼塊であり，Alを $5 \mathrm{~kg} / \mathrm{t}$ まで加えている. Table 2 の試料は窒化マンガンを添加して N を 0.016〜0・021\% 含有させたものである.

\section{2) 熱処理}

まず，鋳造のままの鋼塊から削り出した試験片を，熱

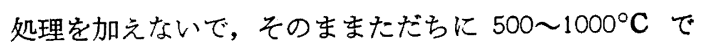
引張試験した。

つぎにおよそ 1250 〜 $90^{\circ} \mathrm{C}$ で鉎造した丸棒材から 試験片をとり，Ar ガスを流した $1350^{\circ} \mathrm{C}$ の前熱処理师 に入れ, $30 \mathrm{mn}$ 保持したのち, $150^{\circ} \mathrm{C} / \mathrm{h}$ の速度で徐冷 し, 徐冷中にすばやく引張試験機にとりつけた炬に移し て引張試験を行なつた。 また, 徐冷しないで,すばやく 引張試験機の炉に移し, 試験片が炉の温度まで急冷する のをまつて引張試験を行なつた.

さらに，鍛造材に前熱処理を加えないで，そのままた だちに 500〜 $1000^{\circ} \mathrm{C}$ で引張試験を行なつた。

3) その他

高温引張試験装置は前報1とおなじものを使用した. 引張試験片の形状は, 径 $6 \mathrm{~mm}$, 伸び標点距離 $20 \mathrm{~mm}$, 全長 $50 \mathrm{~mm}$ の小試片である.

溶接割れの調査には,アーク溶接による熱影響部割れ 試験法の一つである, いわゆる C T S 割れ試験片む)を供

Table 1. Chemical composition of $50 \mathrm{~kg}$ steel ingots used for study. (Melted in a high-frequency induction furnace and as cast)

\begin{tabular}{c|c|c|c|c|c|c|c|c}
\hline \hline Sample & C \% & Si $\%$ & Mn $\%$ & P \% & S\% & $\begin{array}{c}\text { Acid-soluble } \\
\text { Al\% }\end{array}$ & Total N\% & N as AlN \% \\
\hline A & 0.19 & 0.25 & 1.19 & 0.011 & 0.019 & 0.001 & 0.006 & 0.000 \\
B & 0.21 & 0.30 & 1.22 & 0.012 & 0.025 & 0.011 & 0.006 & 0.003 \\
C & 0.23 & 0.31 & 1.35 & 0.015 & 0.021 & 0.042 & 0.008 & 0.005 \\
D & 0.19 & 0.30 & 1.34 & 0.013 & 0.020 & 0.125 & 0.007 & 0.004 \\
E & 0.19 & 0.33 & 1.35 & 0.013 & 0.024 & 0.315 & 0.008 & 0.005 \\
\hline
\end{tabular}

Table 2. Chemical composition of $50 \mathrm{~kg}$ steel ingots used for study. (Melted in the high-frequency furnace, as cast and containing higher nitrogen content.)

\begin{tabular}{c|c|c|c|c|c|c|c|c}
\hline \hline Sample & C $\%$ & Si $\%$ & Mn $\%$ & P\% & S\% & $\begin{array}{c}\text { Acid-soluble } \\
\text { Al\% }\end{array}$ & Total N\% & N as AlN \% \\
\hline 1 & 0.21 & 0.24 & 1.20 & 0.013 & 0.020 & 0.003 & 0.019 & 0.001 \\
2 & 0.19 & 0.28 & 1.35 & 0.015 & 0.022 & 0.012 & 0.021 & 0.005 \\
3 & 0.20 & 0.29 & 1.36 & 0.016 & 0.021 & 0.050 & .0 .017 & 0.012 \\
4 & 0.22 & 0.32 & 1.43 & 0.016 & 0.023 & 0.130 & 0.019 & 0.014 \\
5 & 0.18 & 0.30 & 1.40 & 0.015 & 0.022 & 0.300 & 0.016 & 0.014 \\
\hline
\end{tabular}




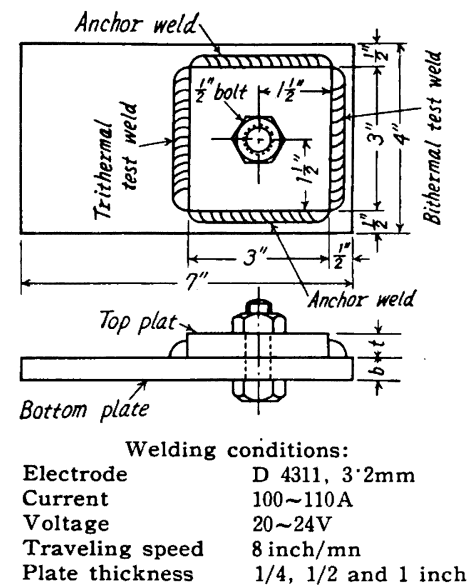

Fig. 1. Shape of C.T.S. (controlled thermal severity) test specimen and the welding conditions.

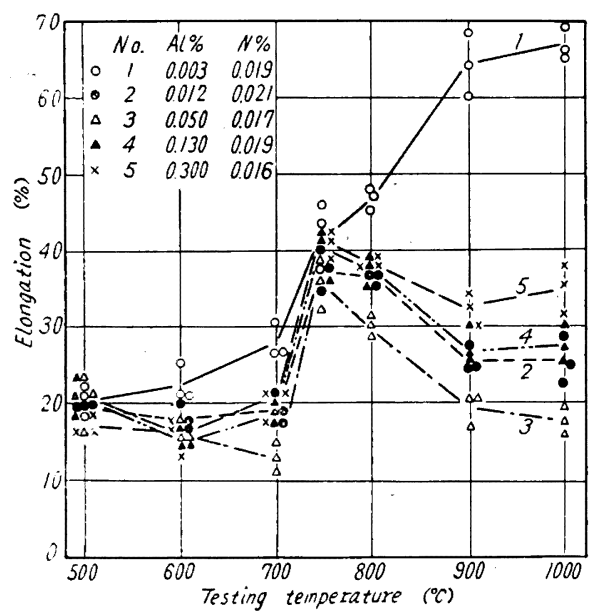

Fig. 2. Effect of aluminum content on the high-temperature elongation of the lowcarbon steels shown in Table 2.

The test piecies without notch were made from the $50 \mathrm{~kg}$ ingots as cast and drawn without preheat-treatment.

試して, 熱影響部付近の A1N の析出形態について観察 した. Fig. 1 にCTS 割れ試験片の形状を示した.

\section{III. 低岩素鋼の高温延性と AIN の形笖}

1) 鋳造材

Table 2 の鋳造のままの鋼塊からとつた試験片による 伸びおよび絞りの变化を Fig. 2 および 3 亿示す.

引張強さには，A1 の添加の影響はほとえどみられな いが, 伸びおよび絞りは 600〜700 $\mathrm{C}$ および 800〜1000

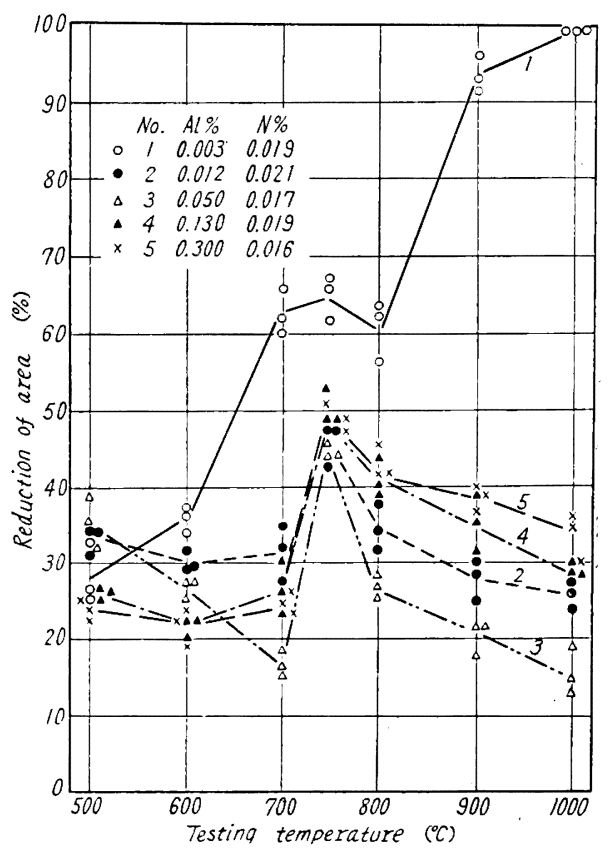

Fig. 3. Effect of aluminum content on the recuction of area of the steels at high temperature as shown in Table 2. The same test pieces as in Fig. 2 were used and cirawn without preheattrcatment.

'Cでいちじるしく低下している. $750^{\circ} \mathrm{C}$ では，わずか しか低下しない，前報1の中炭素鋼の場合と流，Ec0 C C 以下の延性が高い点が異なつている.

また，酸可溶の A1 が 0.050\% の試料 [3] がもつと も低い延性を示し,酸可溶の $\mathrm{Al}$ がそれより少ない試料, あるいは逆に多い試料では高い值を示している。

Nの含有量の少ない Table 1 の鋼塊からとつた試験 片による結果も，これとほとえどおなじ傾向であつた。

Photo. 1 は $700^{\circ} \mathrm{C}$ で引張試験した試料 [3] から， カーボンレプリカ膜上に抽出された AlN である. 鋼塊! 凝固後の冷却中に，オーステナイトの粒界に析出したと 思われる AlN の析出線と，フェライト中に析出したと 思われる分散した AlN が認められる.

このように低炭素鋼においても，Al の添加によつて 高温延性がいちじるしく低下することが認められたが, このような高温延性低下の原因は A1N の析出によるも のと思われる.すなわち, 中炭素鋼の場合1)とおなじく， オーステナイト域では分散して析出した AlN が，また フエライト・パーライト域では硬いパーライトが析出し て, 一次オーステナィトの粒界に析出した AlN の析出; 


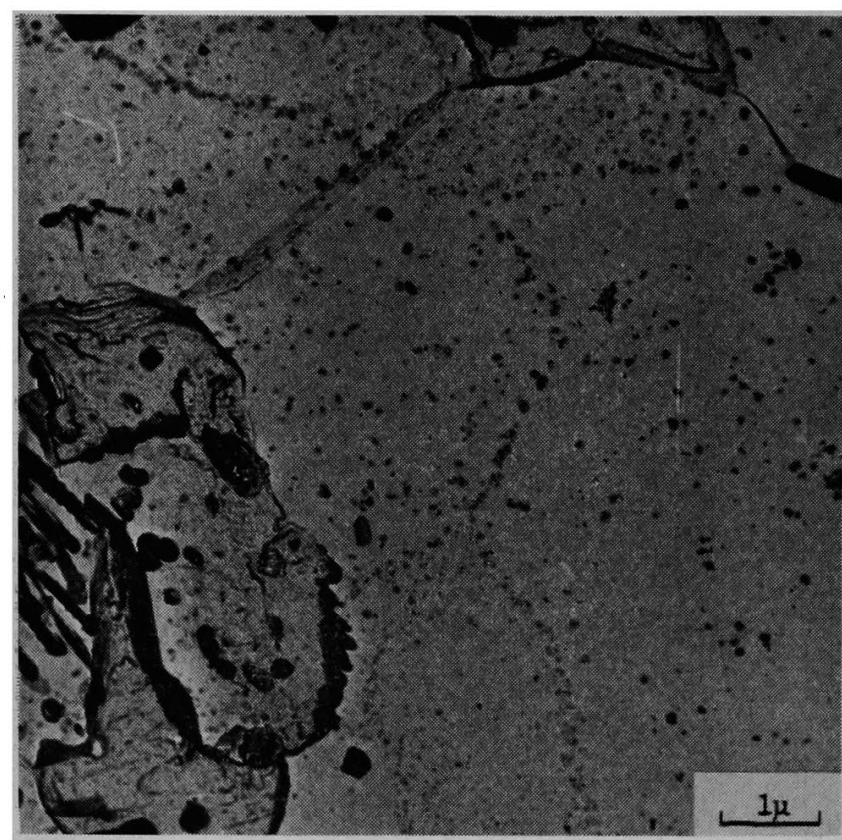

Photo. 1. Lines of small aluminum nitride (AIN) precipitates extracted by carbon replica from the tensile test piece, which was made from the $50 \mathrm{~kg}$ ingot (Sample 3 shown in Table 2) as cast and drawn at $700^{\circ} \mathrm{C}$ without preheat-treatment.

線に沿つた破断を起すものと考えられる。なお，フェラ イト・パーライト域では $600 \sim 700^{\circ} \mathrm{C}$ で, オーステナイ 卜域では $1000^{\circ} \mathrm{C}$ 前後で, 延性がもつとも低くなつてい るが，これはつぎの諸因子の綜合された影響によるもの であろう・

a ） A1N の析出線が存在する部分と, その他の部分 との相対的な強度の变化

b) $A_{1}$ および $A_{3}$ 変態

c ) $\mathrm{AlN}$ の凝集

d) 変形および加熱による A1N の新しい析出

2) 鍛 造 材

Table 2 の試料による固溶処理後徐冷中の絞りの变 化を Fig. 4 に示す. Fig. 3 の鋳造のままの試料のよ うな，Al の添加による延性の低下はここでは認められ ない.

また，鋳造のままの場合より全体に延性は高く, 850 ${ }^{\circ} \mathrm{C}$ 付近に延性の谷がみられるが, 中炭素鋼の場合1)に みられた $700^{\circ} \mathrm{C}$ 以下での延性の低下はみられず，とく に絞りは $650^{\circ} \mathrm{C}$ 前後でいちじるしく高くなつている. $500^{\circ} \mathrm{C}$ での延性は $\mathrm{Al}$ を添加したものの方がかえつて高 くなつている.
Fig. 5 はおなじくTable 2 の試料による 固溶処理後急冷中の絞りの变化を示したもの である。

徐冷の場合より延性は全体にく低く,また, $850^{\circ} \mathrm{C}$ 以上の高温側と $600^{\circ} \mathrm{C}$ 前後では, $\mathrm{Al}$ を添加したものは延性がかなり低下してい る. 中炭素鋼の場合 ${ }^{1)}$ と比較子れば, $700^{\circ} \mathrm{C}$ 以下の延性はかなり高く, 中炭素鋼では 600 $\sim 650^{\circ} \mathrm{C}$ に最低点がみられたのに反して,低 炭素鋼では $650^{\circ} \mathrm{C}$ 前後で最高の延性を示し ている。

Photo. 2 は Table 2 の試料 [3] の急 泠中 $1000^{\circ} \mathrm{C}$ の引張試験片から抽出された A1N を示したものである. 長さ $0.5 \mu$ 前後 の板状の A1N が連らなつて析出している.

鍛造材に上のような前熱処理を加えない で,そのままただちに引張試験したときには， Al を添加した試料では, $900^{\circ} \mathrm{C}$ 以上の高温 側の延性がいらじるしく低下する場合がみら れた。

固溶処理後急冷の場合に, $850^{\circ} \mathrm{C}$ 以上の高 温側の延性が A1 の添加によつて低下してい るが, これは, Photo. 2 に示したようなオ ーステナイトの粒界に析出したと思われる A1N の析出 線に沿う破断によるものであろう. 引張試験中の变形に よる新しい微細な AlN の析出が，オーステナイト粒内 での変形を阻止する効果もこれに加わつているものと考 えられる.

固溶処理後徐冷の場合も急冷の場合も, ともに $650^{\circ} \mathrm{C}$ 前後の延性, とくに絞りが高い点が中炭素鋼の場合 ${ }^{1)}$ いちじるしく異なつているが，これは，低炭素鋼では冷 却中に網状フェラィトが形成されないので, 冷却中に析 出した A1N に変形が集中することがないためと考えら れる. 急冷の場合には, $600^{\circ} \mathrm{C}$ 前後の延性が $\mathrm{Al}$ の添加 によつて低下しているが，これは，冷却中におもにフェ ライト域で微細な A1N が析出し, さらに, 引張試験中 の変形による新しい A1N の析出があつて, 硬化するた めであろう.なお, 徐泠した場合の $500^{\circ} \mathrm{C}$ の延性は, Al を添加したものの方が高いが，これは，フェライト 粒が微細であるためと思われる. また, 徐冷中の $850^{\circ} \mathrm{C}$ での延性が, Al を添加しない試料でも, 中炭素鋼の場 合〉よりかなり低下しているが，これは，低炭素鋼では $850^{\circ} \mathrm{C}$ ですでにフェライトがオーステナイトと共存する ためであろう. 


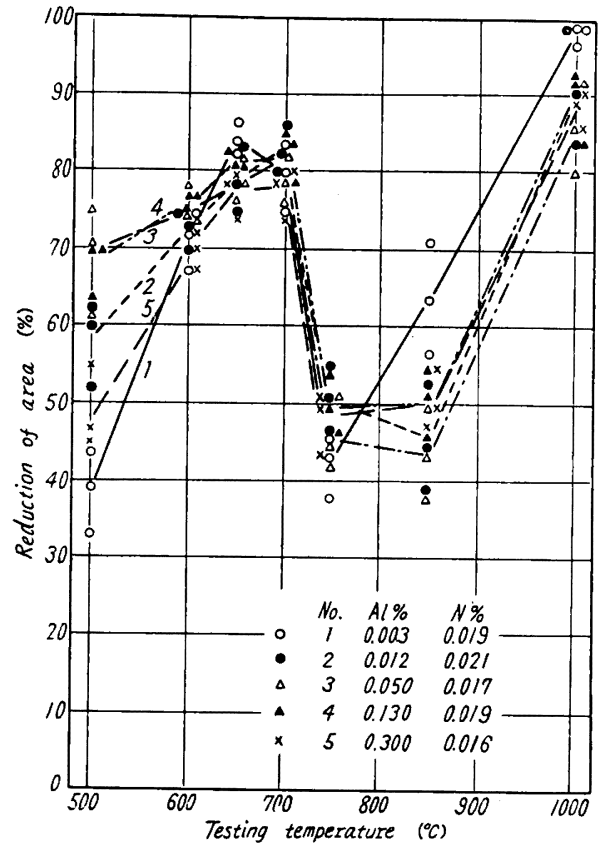

Fig. 4. Effect of aluminum content on the reduction of area of the steels at high temperature as shown in Table 2 .

The test pieces without notch were made from a forged bar, heated for 30 $\mathrm{mn}$ at $1350^{\circ} \mathrm{C}$ in order to dissolve the precipitates of aluminum nitride(AlN), cooled slowly (cooling rate $150^{\circ} \mathrm{C} / \mathrm{h}$ ) to $1000 \sim 500^{\circ} \mathrm{C}$ and then drawn.

固溶処理をしないで引張試験したときには，A1 の添 加によつて高温側での延性が低下しているが，これは， 鍛造温度へ加熱した後の冷却時にオーステナィトの粒界 に析出した AlN と, 引張試験中の変形によつて新しく 析出する AlN の両者が原因しているすのと思われる.

\section{IV. 溶接割れにおよぼす AIN の影響}

溶接構造用鋼のアーク溶接による熱影響部割れにおよ ぼす Al の添加の影響については, さきに実験を行な い4, いわゆるCT S 割れ試験において, SIMS ら5の報 告とおなじく, 酸可溶の $\mathrm{A} 1$ が 0.01〜0.02\% のとき割 れがもつとも発生しやすく，A1 がそれより多くとも少 なくとも割れが減少することを認めた．また，Nを0・02 〜0.03\% と故意に多く添加した試料，すなわち A1N の 析出量の多い試料の方が割れの発生が少なくなることが 判つたが，この現象はバッテル割れ試験（これも溶接熱 影響部割れ試験法の一つ) でとくに明瞭に認められた。 A1 の添加量が比較的多い場合に熱影響部割れが減少

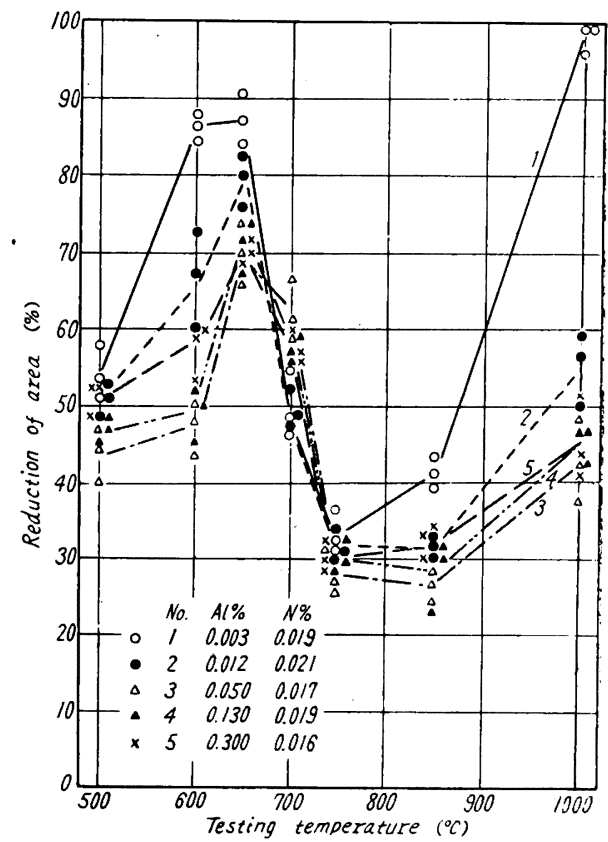

Fig. 5. Effect of aluminum content on the reduuction of area of the steels at high temperature as shown in Table 2.

The test pieces without notch were made from a forged bar, heated for $30 \mathrm{mn}$ at $1350^{\circ} \mathrm{C}$, cooled rapidly to $1000 \sim 500^{\circ} \mathrm{C}$ and then drawn.

するのは, AIN が急冷時の変態を促進(6)7), また, 結 晶組織を微細にするためではないかと考えられるが，AI を添加しない場合，あるいは Al が少ない場合に，熱影 響部割れが減少する機構は明らかでない。

C T S 割れ試験片を供試して, 熱影響部付近の AIN を抽出レプリカによつて観察した.

Photo. 3 は CTS 割れ試験片にみられた大型の熱 影響部割れを示したものである. 多くは溶融面に平行な 横割れである。

熱影響をうけない母材部では，AIN はフエライトと パーライトの中に分散して析出しているが，溶接による 熱影響のために，溶着鋼に近い熱影響部では，AINの 一部あるいは全部が溶解している. 溶着鋼の部分は球状 の介在物の存在と組織とによつてそれであることがわか る. 酸可溶の A1を 0.05\% 以上含有する試料では, AlN の一部分のみが溶解し, 溶着鋼直下の熱影䌟部に むなお A1N が散在しているのがみられる.

このような Al の量による差異は, A1 の多い試料ほ ど A1N の固溶温度が高いためと思われる.

また，熱影響部に残留して散在している AIN が，溶 


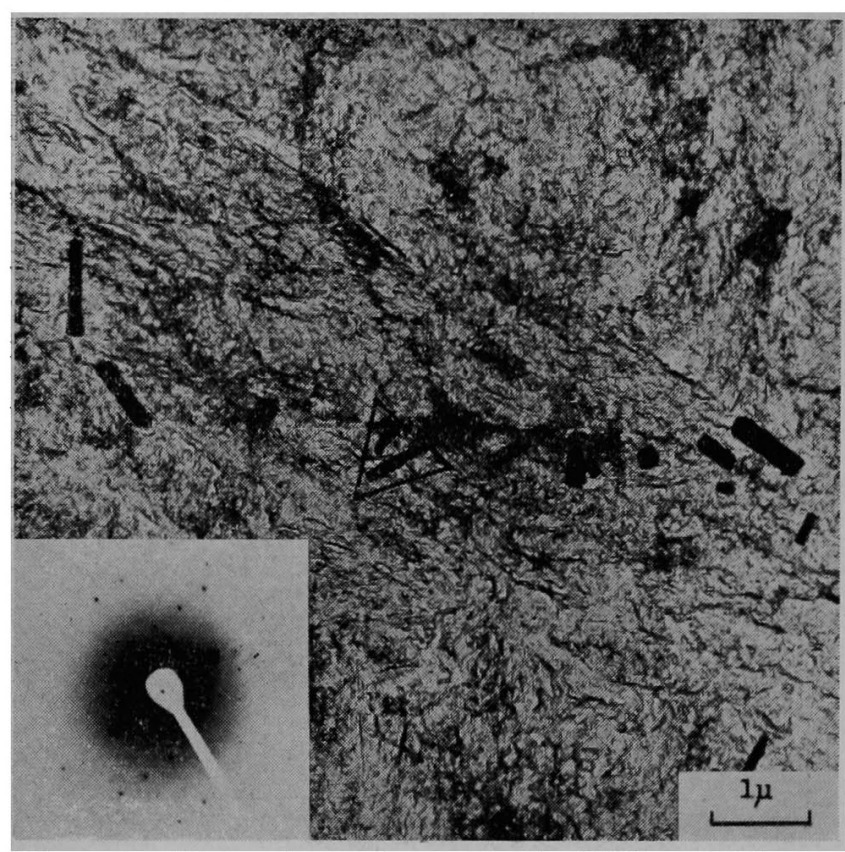

Photo. 2. Lines of aluminum nitride (AlN) precipitates extracted by carbon replica from the tensile test piece, which was made from a forged bar (Sample 3 shown in Table 2) as cast, heated for $30 \mathrm{mn}$ at $1350^{\circ} \mathrm{C}$ in order to dissolve aluminum nitride, cooled rapidly to $1000 \sim 500^{\circ} \mathrm{C}$ and then drawn.

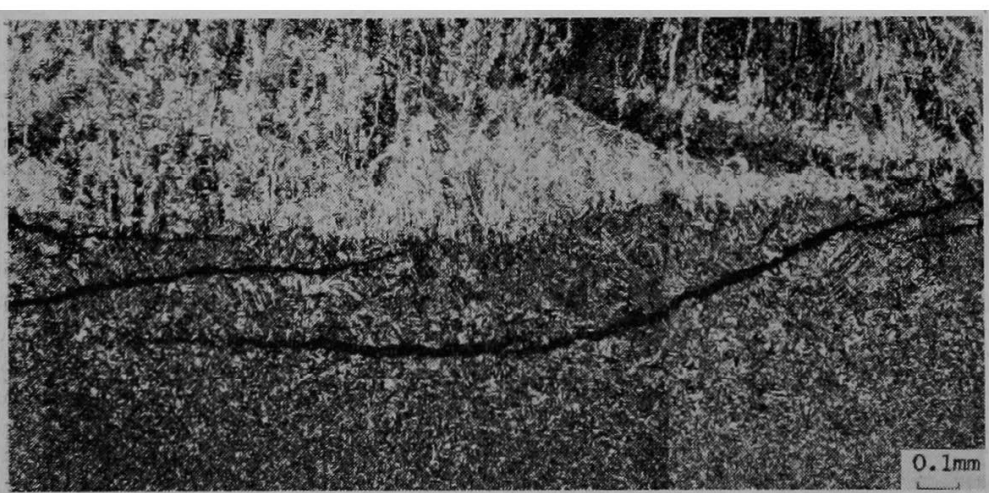

Photo. 3. Welding cracks in the heat-affected zone of the low-carbon steel observed in the specimen of C.T.S. test. る.
後の冷却時に収縮するときの高温舶裂の原因 となるのではないかと考えられる・したがつ $・ て$, 熱影響部割れが Al の少量の添加によつ てかえつて増加する現象は，上に述べたよう な高温延性の低下と関連があるものと思われ

以上は鍛造材の場合であるが，鋳造材の場 合には，鍛造材よりも割れが多く発生し， た，鍛造材のような $\mathrm{A} 1$ の添加の効果は認め られなかつだ、。

これは, Photo. 1 に示したような鋼塊の 凝固後の冷却中にオーステナイトの粒界に析 出した AlN の析出線, なうびに網状の硫化 物系介在物によるものと考元られる.

すなわち, AlN の析出線は高温延性をFig. 2 および3に示したようにいちじるしく低下 させるし，また，網状の硫化物の存在が高温 割れを増加させることは, J. M. MiddLETON ら 8) 10)によつて明らかにされている.

\section{V. 総括}

以上のように，低炭素鋼の高温延性ならび に溶接熱影響部割れにも A1N が影響をおよ ぼしていることを明らかにしたが，つぎに本 報における調査の結果を総括し た.

1）A1 の添加は鋳造のま。まの 低炭素鋼の高温延性をいちじるし く低下させる. $800^{\circ} \mathrm{C}$ 以下の延性 が高いことが，中炭素銅の場合と 相異している.

2 ）鉡造材および鍛造材の固溶 処理後急冷中の $850^{\circ} \mathrm{C}$ 以上に打 ける延性は，A1 の添加によって 低下する. 固溶処理後徐泠中の延 性には，中炭素鋼にみられたよう な $\mathrm{Al}$ の添加による低下はみられ 接熱により急熱された後の冷却時に变態を促進して割れ を少なくすることが考えられるＣＣＴＳ割れ試験および バツテル割れ試験において, Al および $\mathrm{N}$ を多量に添加 すると熱影響部割れがかなり減少したのは，このような AlN の効果によるものであろう.

一方, 低炭素鋼の高温延性が A1 の添加によつてかな り低下することがあることを上に示したが，このような 高温延性の低下は，溶接熱により加熱された部分が溶接
ず，500ㄷでは $\mathrm{Al}$ を添加した試料の方がかえつて高い 延性を示す．鍛造材を固溶処理しないで試験した場合に も, $\mathrm{Al}$ の添加によつて $850^{\circ} \mathrm{C}$ 以上における延性が低下 するのがみられた。

3）このような $\mathrm{A} 1$ の添加による高温延性の低下は, A1N の析出形態と密接な関係があることを示した。

4) A1 およびNの添加量の多い試料では, 溶着鋼直 下の溶接熱影響部には，溶解しないで残つている AlN 
が散在しているが，A1 および $\mathrm{N}$ の少ない試料では，溶 接熱のために AlN は溶解してしまう. Al およびNを 多量添加すると熱影響部割れが 減少するのは, AlN の一部分のみが溶解し, 溶解しないで熱影響部に残留し て散在している A1N が泠却時の変態を促進するためと 考えられる。

5 ）溶接熱影響部割れ は酸可溶の A1 が $0.01 〜 0.02$ \%前後までは増加する場合があるが，これは，Al の添 加によつて高温延性が低下する現象と関連があるものと 思われる．溶接後の収縮量が大きい場合には，AINの析 出による悪影響がつよくあらわれて高温亀裂を発生さ せ,これが起点となつて熱影響部の低温割れを増加させ るのではないかと考えられる.

6）鋳造材では熱影響部割れの発生が鍛造材よりも多 く, また, Al の添加が割れを減少させる効果も認めら れないが, これは, AlN の析出線と硫化物系介在物に よる高温延性の低下に関係があるすのと思われる.

おわりに，本研究を行なうにあたり御指導を賜わつた 名古屋大学教授武田修三博士に対しあつく感謝の意を表 します。また，住友金属工業株式会社中央技術研究所の
上司の方々の御指導と, 和歌山製鉄所試験課柳沢睦郎お よび岩谷旭両君の協力により行なわれたことを記して感 謝の意を表します。

(昭和 37 年 3 月寄稿)

\section{交献}

1) 長谷部: 鉄と鎆, 48 (1962), p. 761〜770

2) A. Straky: Stahl u. Eisen, 77 (1957.), p. 778

3 ) H. Wiester, W. Bading, H. Riedel u. W. Scrolz: Stahl u. Eisen, 77 (1957), p. $773 \sim 784$

4) 長谷部: 溶接学会誌, 28 (1959), p. $511 \sim 516$

5 ) C. E. Sims a. H. M. BAnTA: Welding J., 28 (1949), p. 178-s 178 192-s

6) M. A. Grossmann: Element of Hardenability, Amer. Soc. Metals, (1950), p. 150

7 ) 米谷: 日本金屈学会誌, 23 (1959), p. 317

8 ) J. M. Middleton a. H. T. Protheroe: J. Iron \& Steel Inst. (U.K.), 168 (1951), p. $384 \sim 400$

9 ) C. E. Sims, H. A. Saller a. F. W. Boulger: Trans. Amer. Foundrymen's Assoc., 57 (1949), p. 233 248

10) W. J. Phillips: Foundry, 97 (1940), p. 27 $\sim 28,87 \sim 88$

\title{
$\mathrm{Cr}-\mathrm{Ni}$ ステンレス鋼の耐食性におよぼす
}

\section{成分および組織の影響*}

(Ni, Mo の影響)

\author{
乙黒靖男 $* *$ 河部義邦** $\cdot$ 中川龍一*** \\ Effects of Composition and Structural Conditions on Corrosion \\ Resistance of $\mathrm{Cr}-\mathrm{Ni}$ Stainless Steels. \\ (Effect of $\mathrm{Ni}$ and Mo additions) \\ Yasuo Otoguro, Yoshikuni KawaBe and Ryuichi NakAgAwa
}

\section{Synopsis:}

In the previous report (Tetsu-to-Hagané, 48 (1962)6, p. 776), the anthors reported the effect of $\mathrm{Ni}$ and $\mathrm{Mo}$ content on structures of $\mathrm{Ni}-\mathrm{Cr}$ stainless steels and the effects of structures on mechanical properties.

This paper describes the effects of structures, mainly those of $\delta$ ferrite on corrosion resistance to nitric acid and sulfuric acid and also describes the relation between corrosion potential in both acids and compositions and structural conditions.

Precipitation of chromium carbide and decomposition of $\delta$ ferrite to $\sigma$ phase resulted in an increase in corrosion rate in nitric acid.

* 昭和 36 年10月本会講演大会にて発表 ** 金属材料技術研究所 $* * *$ 金属材料技術研究所 工博 